\title{
Investigations of temperature and dilution effect on rheological properties of waxy crude oil
}

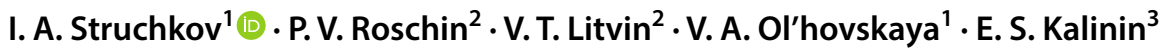

Received: 19 March 2019 / Accepted: 19 September 2019 / Published online: 25 September 2019

(c) The Author(s) 2019

\begin{abstract}
The purpose of the paper is to study the effect of temperature and hydrocarbon solvent addition on thixotropy of waxy crude oil. Oil is a complex multicomponent hydrocarbon system. There are many interactions between wax and asphaltene, wax and aromatics, asphaltene and resins in original oil. For example, the dispersion of asphaltenes is known to be influenced by resins. The resins are adsorbed onto the surface of the asphaltenes, whereby the asphaltenes are not aggregated. Wax is adsorbed by fine asphaltene particles and wax appearance temperature (WAT) observed at low temperature (formed wax crystals too small to be detected by measuring system). The authors of the paper have studied the separate effect of two solvents (kerosene and diesel fuel), wax concentration and impurities (kaolinite) on WAT to understand how all these factors affect WAT in wax-bearing solutions individually. Wax-bearing solutions in wax concentration range from 10 to $60 \%$ by weight were investigated by the visual and rheological methods under atmospheric pressure. It is shown that the diesel-based solutions have higher WAT than the kerosene-based solutions. Studies have shown that the increase in wax concentration in solution leads to an increase in WAT. The paper describes that the addition of impurities (kaolinite) to the solutions resulted in an increase in WAT. Besides, it is shown that WAT obtained by rheological method is higher on average of $1^{\circ} \mathrm{C}$ than WAT obtained by visual method. The authors suggested that under constant other conditions (pressure, resin and asphaltenes content, etc.) an increase in wax content in oil and the content of impurities will lead to an increase in WAT. The scientific basis for this conclusion is that, in the future we can, adding or removing from solution hydrocarbon components, with certain assumptions, simulate the properties of oil. In particular, this will allow us to study separate interactions between the wax and asphaltene, wax and aromatics, and wax and naphtha compounds, and abstract away from other factors. The waxy crude oil production in the Samara region is complicated by impurities entrainment and non-Newtonian properties of oil. The investigations of waxy crude oil were provided with light scattering method (in near infrared region), microscopy under high pressure with the grain size analysis (visual) and a rheological method. We obtained the unique «viscosity superanomaly» discovered by Vinogradov and Malkin (Rheol Acta 5(3):188-193, 1966) at low temperatures and shear stress by rheological method under atmospheric pressure. The area of the hysteresis loop on the flow curve increases as the temperature decreases, which is caused by the formation of the lattice by wax. We have also shown that the use of solvent and the increase in temperature allow to reduce «viscosity superanomaly». Simultaneous use of light scattering and microscopy under high-pressure methods allows increasing in accuracy of measuring. For waxy crude oil, there will also be a difference between rheological and visual methods of WAT measuring, as these methods have different sensitivity limits. Besides, the study showed that addition of $\mathrm{N}_{2}$ and $\mathrm{CO}_{2}$ to oil leads to decrease in WAT. However, it is necessary to provide a number of additional studies before gas injection projects in the field. For example, it is shown that $\mathrm{CO}_{2}$ injection leads to asphaltenes precipitation in oil by many scientists. Novelty of the paper consists in investigation of rheological properties of waxy crude oil of the Samara and the effect of nonhydrocarbon gases on WAT. In this study, unique flow curves of oil of the Samara region were obtained.
\end{abstract}

Keywords Organic scales $\cdot$ Impurities $\cdot$ Nitrogen $\cdot$ Carbon dioxide $\cdot$ Waxy crude oil

I. A. Struchkov

StruchkovIA@gmail.com

Extended author information available on the last page of the article 


\section{Introduction}

Waxy oil production is associated with organic scale formation in the field (Mansoori 1997; Goual 2012; Idris and Okoro 2013). There are impurities (formation particles, frac sand, scales, corrosion products) in oil caused by higher draw down, a poor consolidation of rock, technological features of remedial stimulation, etc. Impurities lead to formation of complex scales which are difficult to remove during all production phases. Petroleum engineers provide comprehensive investigations and effectively handling wax deposition, making sure prevention of flow assurance failure. There are many wax prediction models (Bern et al. 1980; Brown et al. 1993; Singh et al. 2000) based on foundational mechanisms (molecular diffusion, shear dispersion) and results of routine and special oil studies (measurement of oil viscosity, density, wax appearance temperature, wax disappearance temperature, etc.) carried out at high-pressure/temperature conditions. Reliability of such models depends on the accuracy of measured oil properties. Detailed study of factors that affect WAT in oil will allow precisely evaluating time and potential wax formation area in the tubing, to increase the run time of oil wells by application of the most suitable wax deposition control methods. The rapid test methods help resolve any technical problems, related to organic scale formation in the field. Rheological, light scattering and visual methods act as the most available and user-friendly laboratory techniques ( $\mathrm{Li}$ and Gong 2010). At the same time, nondestructive testing methods aimed to wax thickness measurements allow to obtain data about potential blockage areas in the pipes and thus to avoid any sudden shutdown in the flow. Different research methods show different WAT results. This is due to the sensitivity of the measuring system and the measuring technique. Several independent investigation methods need to be used to describe the wax crystallization in petroleum in more detail (Kok et al. 1996; Struchkov and Rogachev 2017a, b).

The main techniques of measuring the wax deposition are:

- cold finger testing (Chi et al. 2017);

- pressure difference method. The conventional technique is flow loop testing (Amine et al. 2008);

- temperature-based energy balance method (Halstensen et al. 2013);

- ultrasonic transit time measurement (Gunarathne 1995).

The first one can have different testing conditions (shear rates, temperature gradients and pressure) compared to petroleum pipelines. However, despite a significant drawback, this conventional method remains common, as it requires a small amount of oil sample; it is easy to operate and cheap. Pressure difference method cannot identify the blockage area. Electric capacitance tomography allows obtaining the high-quality images that take a lot of time. Temperature-based method enables to predict the wax thickness in pipeline in real time. Utilization of ultrasonic transit time-based method has difficulties with interpretation of the obtained data because the sound velocity within the wax scales is unknown.

In the global experience of oil and gas industry, a large number of methods oriented to prevention and remediation of organic scales are known (Mansoori 1997; Idris and Okoro 2013; Struchkov and Rogachev 2018; Struchkov et al. 2016, 2018, 2019):

- chemical methods;

- thermal methods;

- application of protective covers;

- electromagnetic methods;

- vibration methods.

Chemicals influence the nature of interaction between high molecular weight components of oil and allow controlling organic scale formation. The hot topic is development of the multipurpose chemicals which allow simultaneous controlling several technical problems (for example organic scales, scales, corrosion products, etc.). In the electrochemical corrosion process, the formation of corrosion products results from the anode and cathode reactions. It is known the tubing has a natural magnetism. In the electromagnetic field, corrosion products (which tear away from the metal surface and are suspended in oil) can be oriented in the magnetic field and act as nucleation seeds of wax. Those corrosion products that remain onto the metal surface have a greater area and roughness than the metal of the pipe, which has a beneficial effect on wax crystallization and deposition. Chemical methods are marked by the high cost of reagents and the presence of toxic components in composition which have a harmful effect on field engineers. The reagents used may act as emulsifiers. This will increase the cost of oil processing. Furthermore, individual screening of reagents to oils with different physical and chemical properties is required. On the one hand, petrochemicals such as gas condensate, gasoline, diesel, light crude oil are necessary to use which do not influence oil processing; however, such agents not always allow controlling organic scale formation effectively (Zadeh et al. 2018). Some reagents may improve metal removal which poisons the catalysts and plugs the catalyst beds needed to heavy oil processing (Lordo et al. 2008; Kapusta et al. 2003). 
Disadvantages of thermal methods involve short duration of effect and applicability limitations (Halvorsen et al. 2000).

Disadvantages of protective covers that consist in that coatings such as enamels, resins, glass are crumbly, they are hard to coat the inner surface of pipes, and they destroy under weighting and deformations.

Electromagnetic methods are successfully used in a number of fields of LLC Orenburgneft. However, operation of magnetic devices based on permanent magnets (magnetic source) made of rare metals is complicated with a large amount of impurities in oil, higher gas oil ratio, etc. (Gudmundsson and Bott 1977). This magnetic radiation is characterized by significantly lower energy compared to microwave and ultrasonic waves, which is insufficient to disaggregate organic scales. Microwave and ultrasonic irradiation causes an increase in the temperature of the heavy oil sample. Such oils show nonNewtonian properties under ambient conditions, and the high temperature destroys the bonds formed between wax-asphaltene-resin compounds. Therefore, microwave and ultrasonic irradiation leads to a decrease in the viscosity of heavy oil (Taheri-Shakib et al. 2017a, b). There was a gradual decrease in the cluster size of asphaltene as radiation time increased (Taheri-Shakib et al. 2017a, b). Thus, the amount of asphaltene particles in oil increases when exposure time under radiation increases. Moreover, asphaltene particles act as nucleation seeds of wax. As the temperature decreases, wax is absorbed by fine asphaltene particles so that the formed aggregates (wax-asphaltene) can be detected by the measuring system at lower temperature. In other words, WAT decreases with an increase in exposure time under radiation (Taheri-Shakib et al. 2018a, b).

Vibration methods are not applicable resulting from high accident risks based on the resonance phenomena (Gudmundsson and Bott 1977).

Oil is represented by the complex disperse system in which variety of properties primarily are specified by composition. Nowadays, researchers find convenient to describe the whole variety of disperse system combinations using all technologic tools available, as well as to identify the role of each system element individually to change its properties. Therefore, it is reasonable to investigate solutions that showed any separate oil properties to study effect of experimental conditions on wax crystallization. Thus, it will be possible to investigate influence of separate factors on the test property of system. It makes the best use of wax-bearing solutions in hydrocarbon solvent (kerosene, diesel fuel, etc.) to avoid the multivariate analysis studying wax precipitation in oil under various conditions. Wax crystallization in the wax-bearing solutions is studied by the following authors (Gudmundsson and Bott 1977; Al-Ahmad et al. 1990; Srivastava et al. 1997; Wu et al. 2002; Parthasarathi and Mehrotra 2005; Fong and Mehrotra 2007); however, they have not studied influence of many factors such as impurities, inhibitors, gases on wax appearance temperature.

The effect of wax concentration and impurities (kaolinite) on WAT in the solutions by visual and rheological methods has been investigated in the paper. Rheological properties of waxy crude oil, influence of solvent on thixotropic oil properties and influence of nitrogen $\left(\mathrm{N}_{2}\right)$ and carbon dioxide $\left(\mathrm{CO}_{2}\right)$ on WAT are investigated. These experiments are provided by visual, rheological and light scattering methods according to paper (Al-Ahmad et al. 1990).

\section{Oil field overview}

Oil which contains wax in concentration of more than $6 \%$ by weight is related to waxy type according to Russian classification. Oil which contains wax in concentration of 1.5-6\% by weight is related to medium waxy type, and oil which contains wax in concentration of less than $1.5 \%$ by weight is related to low waxy type.

The field data in the Samara region show that $52 \%$ of the number of oil fields are related to medium waxy type. Moreover, in $48 \%$ of oil fields oil wells drilled in formations with waxy oil. Producers of these formations are operated under high draw down with high water cut and impurity content (Struchkov et al. 2016).

Such oil fields as Petrukhnovskoe (wax of $32 \%$ by weight, asphaltenes of $1.9 \%$ by weight, resins of $3.0 \%$ by weight), Volkovskoe (wax of $30 \%$ by weight, resins and asphaltenes of $4.5 \%$ by weight), Padovskoe (wax of $23 \%$ by weight, resins and asphaltenes of $2.7 \%$ by weight) are outlined against reservoirs of the Samara region. The oil production in such fields requires the effective remedial stimulation technologies.

Oil of the Petrukhnovskoe field is characterized by the high wax content ( $32 \%$ by weight), resins and asphaltenes ( $5 \%$ by weight) and gas oil ratio $(133 \mathrm{~m} 3 / \mathrm{m} 3)$. Reservoir is presented by fractured carbonates with low matrix permeability. Reservoir occurs at a depth of $2700 \mathrm{~m}$; formation temperature is $80{ }^{\circ} \mathrm{C}$. Producers in the field operated with artificial lift. Due to the high wax content oil, mobility decreases during production that is complicated with organic scale formation in the downhole equipment and gathering facilities.

Producers in the field are characterized by low flow rates up to $20 \mathrm{~m} 3 /$ day and high water cut up to $90 \%$ (Struchkov et al. 2016). To increase oil production, a number of wells are operated with high draw down. Therefore, liberation of gas on pump suction is observed (pressure on pump suction lower than bubble point pressure on average upon

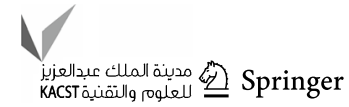


3-13 MPa). High draw down leads to a high gas-oil ratio, sand production and a vast number of impurities in oil (about $60 \mathrm{mg} / \mathrm{l})$. By a number of scientists, it is shown that heterogeneous wax crystallization (at the presence of impurities in oil) thermodynamic is more favorable (Pantell and Puthoff 1969). Impurities change phase equilibrium in oil and increase in WAT (Akbarzadeh et al. 2007; García 2000; Lei et al. 2014). Impurities that accelerate wax crystallization in oil (Brown 1985; Gonzalez et al. 2007; Hirasaki and Chapman 2007) also stimulate organic scale formation of complex composition which is difficult to remove with chemicals. Impurities increase strength of organic scales and oil viscosity under cooling (Al-Ahmad et al. 1990; Gudmundsson and Bott 1977). Overall, it provides improper pump operation and increases operating costs (Goual 2012; Srivastava et al. 1997; Bidmus and Mehrotra 2004; Bortolin and Uzcategui 1992; Kriz and Andersen 2005).

Field experience shows that the main complication with well operation in the field is organic scale formation. Impurity concentration in produced oil varies in the range from 20 to $900 \mathrm{mg} / \mathrm{l}$ in terrigenous reservoirs and up to $400 \mathrm{mg} / \mathrm{l}$ in carbonates of the Samara region.

Mechanical filters, consolidation of semi-consolidated rocks, flushing out of well and simultaneous organic scale and corrosion product control methods can be successfully used to decrease impurity content during oil production.

In the field, the following well stimulations were used: hot oil flushing, well steaming and solvent treatments. Thermal method is the most efficient way for prevention of organic scale formation. So, use the electric heater in wells allowed increasing their run time by $6-7$ times.

It is necessary to investigate crude oil to studying of a real scenario in the field if laboratory equipment allows making it (according to sensitivity of measuring systems).

Oil with the high wax content shows Newtonian properties at reservoir conditions; however, it shows viscosity anomalies under cooling and is characterized by high pour point. The mobility of oil under cooling considerably decreases at production and can be described such rheological parameter as yield stress. The gel structure in oil reduces at yield stress.

\section{Experiments and methods}

\section{Laboratory apparatus}

Investigation of wax crystallization in wax-bearing solutions and oil was carried out by a visual and light scattering method via PVT unit, the main components of which are as follows:
- SDS (solid detection system) PVT (pressure, volume, temperature) cell is a cell for the light scattering method of analysis (Paso et al. 2009; McMullin et al. 1999). Source and receiver of laser energy are located in this cell. In this cell, the studied fluid is mixed up with the magnetic stirrer.

- HPM (high-pressure microscope) cell is a cell for the visual analysis (Hirasaki and Chapman 2007). This cell consists of the box and two sapphire glasses between which the studied fluid circulates. The microscope is located opposite to the cell. The minimum oil volume (using only SDS PVT cell) is $30 \mathrm{ml}$, and the maximum oil volume (using both cells) is $60 \mathrm{ml}$.

- Volume of main pump (P1 in Fig. 1) is $500 \mathrm{ml}$. This pump allows to charge the unit with oil pumping it from the sampler into the cell and to maintain the required pressure during the experiment.

- Volume of recirculating pump (P2 in Fig. 1) is $10 \mathrm{ml}$. This pump allows pumping the studied fluid over a closed-loop PVT-HPM-PVT cell with required flow rate (from 0 to $2 \mathrm{ml} / \mathrm{min}$ ).

- Volume of the injection pump (P3 in Fig. 1) is $500 \mathrm{ml}$. This pump allows injecting chemicals or gases at required concentration into the studied fluid during the experiment.

- Organic solid filter is the filter located at the entrance of the laboratory unit, which allows removing impurities from the studied fluid.

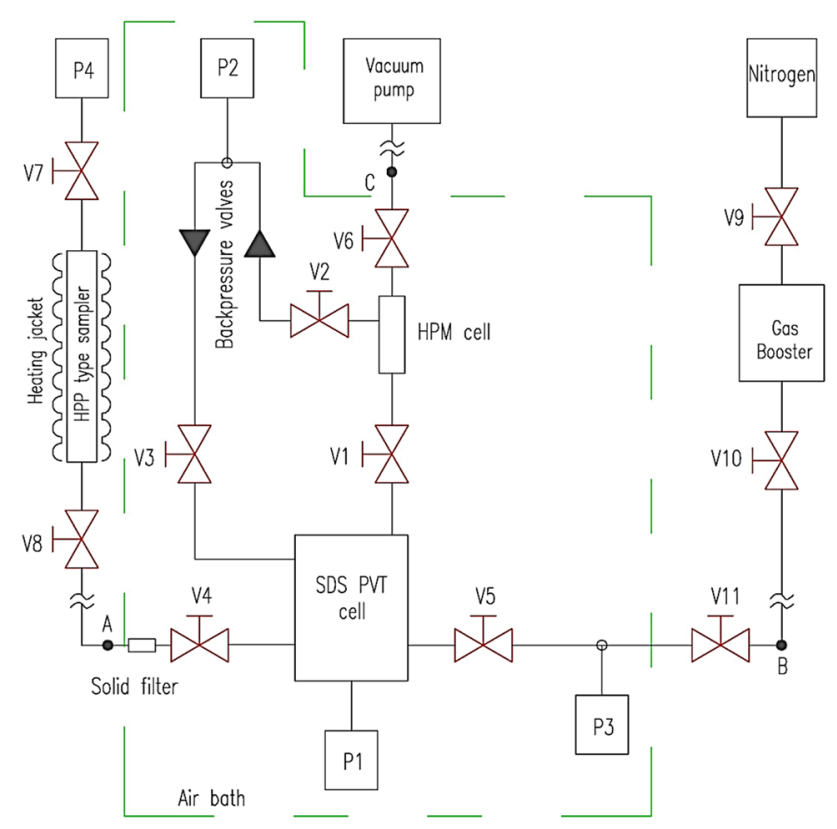

Fig. 1 Schematic diagram of the laboratory unit. (P) - pump, (V)valve, (A, B, C)-connection points for the external equipment (Struchkov and Roschin 2016) 
- Back pressure valves, valves ( $V$ in Fig. 1 ) and tubes with inner diameter of $1 / 8^{\prime \prime}$.

All equipments are placed into the air oven which maintains the required temperature. Operating temperature inside the cells is possible to vary between -20 and $200{ }^{\circ} \mathrm{C}$, and the maximum operating pressure is $69 \mathrm{MPa}$. Experiment data (micrographs, light transmittance power, pressure, volume, temperature) are recorded by the computer each $30 \mathrm{~s}$.

The schematic diagram of the laboratory unit is presented in Fig. 1.

\section{Measurement procedures}

The authors have investigated wax-bearing solutions by visual and rheological methods under atmospheric pressure to estimate influence wax concentration and impurities (kaolinite) on wax precipitation. Kerosene- and diesel-based solutions were prepared with different wax concentrations ranged from 10 to $60 \%$ by weight. This range of wax concentration in solvents has been investigated due to the following reasons. WAT is too low at wax concentration in solvent of less than $10 \%$ by weight. In this case, the study takes a long time. It should be noted that the study is carried out at atmospheric pressure with possible loss of light components (evaporation is possible), so the influence of the experiment duration and temperature on the result of the study is possible. The use of wax in concentration of more than $60 \mathrm{wt} \%$ is unreasonable because the wax-bearing solution is too cloudy. So it is difficult to accurately measure WAT by visual method.

The chemical nature of the solvent affects the result of the study. Both solvents were investigated to show that the dependence of WAT on wax concentration in solution has the similar nature.

There was used kerosene, which is recognized by the ASTM International standard specification D-3699-78 as grade $1-\mathrm{K}$ (less than $0.04 \%$ sulfur by weight) in this study. Kerosene is produced from the fractional distillation of petroleum between 150 and $290{ }^{\circ} \mathrm{C}$ at atmospheric pressure, resulting in a mixture of hydrocarbons with carbon number from C9 to C16. Density of kerosene is $0.78-0.81 \mathrm{~g} / \mathrm{cm}^{3}$; the pour point is standardized at $-47{ }^{\circ} \mathrm{C}$; and gel point is standardized around $-40{ }^{\circ} \mathrm{C}$ (Shepherd et al. 2000).

There was used diesel fuel with the following properties in this study. Diesel composed of hydrocarbons with carbon number from $\mathrm{C} 9$ to $\mathrm{C} 25$ that have boiling point within the range of $200-350{ }^{\circ} \mathrm{C}$ at atmospheric pressure. Diesel is presented approximately by $75 \%$ saturated hydrocarbons and $25 \%$ aromatic hydrocarbons. The gel point of diesel is between $-19{ }^{\circ} \mathrm{C}$ and $-15^{\circ} \mathrm{C}$ (Gürü et al. 2002). Wax is derived from petroleum and presented by the mixture of hydrocarbons with carbon number from 20 to 40 . The melting point of wax is approximately about $52{ }^{\circ} \mathrm{C}$, so it is solid at ambient temperature. Density of wax is around $900 \mathrm{~kg} /$ m3 (Ferris et al. 1931).

\section{Visual method under atmospheric pressure}

Experiments were carried out via HPM cell (Fig. 1) under atmospheric pressure.

- The HPM cell heated to temperature of $70{ }^{\circ} \mathrm{C}$ was vacuumized and charged with wax-bearing solution preheated to temperature at which wax is completely dissolved in solvent $\left(60-70{ }^{\circ} \mathrm{C}\right)$ under ambient pressure.

- Then, the cell was cooled down to $10^{\circ} \mathrm{C}$ below WAT with cooling rate of $0.2{ }^{\circ} \mathrm{C} / \mathrm{min}$. This cooling rate was provided because the laboratory unit uses an air oven that is unable to maintain high cooling rates (Struchkov and Rogatchev 2014). Furthermore, studies are carried out in the cell without loss of light components. Temperature at which the first wax crystal appeared in solution (WAT) was measured due to the micrographs of the sample was recorded by microscope (one data point of WAT for one experiment). The sensitivity of this experimental technique is about $1 \mu \mathrm{m}$.

- Laboratory unit was carefully washed at high temperature with paraffin solvent and dried.

- Then, solution with higher wax concentration was prepared and experiment was repeated.

- As a result, 6 data points of WAT at varied wax concentration in solution were obtained for each solvent (total 12 data points of WAT).

Diesel-based solutions with impurities (kaolinite in three concentrations: $1,0.5$ and $0.1 \mathrm{~g} / \mathrm{l}$ ) were investigated in the same technique as mentioned above (6 data points of WAT per one concentration of kaolinite in solution. Totally, 18 data points of WAT were obtained).

\section{Rheological method under atmospheric pressure}

Experiments were carried out via automatic rotational viscometer (cylinder-cylinder measuring system) under atmospheric pressure.

- The cylinder was charged with required volume of prepared diesel-based solution at single-phase state.

- The following experimental conditions were set: cooling rate was $1{ }^{\circ} \mathrm{C} / \mathrm{min}$ and the shear rate was $2 \mathrm{~s}^{-1}$. This cooling rate was provided since the measuring system is unsealed, oil component loss can be observed, and the duration of the experiment is significant. Therefore,

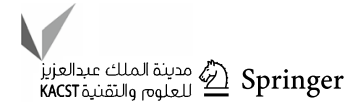


this cooling rate was used for the rheological method to reduce the exposure time of oil at a high temperature, which could affect the result.

- The sample was cooled from 70 to $25^{\circ} \mathrm{C}$.

- The measuring system was carefully cleaned and dried after the end of experiment. Then, the cylinder was charged with other sample with higher wax concentration, and the following experiment was carried out.

As a result, 6 viscosity curves (dependence of effective viscosity on temperature) were obtained. Temperature at which the reflection point appears on viscosity curve was taken as WAT. Diesel-based solutions with impurities (kaolinite in three concentrations: $1,0.5$ and $0.1 \mathrm{~g} / \mathrm{l}$ ) were investigated in the same technique as mentioned above (one viscosity curve per one concentration of kaolinite in solution. Totally, 3 viscosity curves were obtained).

Rheological properties of waxy oil were investigated via rotational viscometer (cylinder-cylinder measuring system). Oil of the Petrukhnovskoe field was assumed as study object. Flow curves' measuring technique (dependence of shear stress on shear rate) was as follows:

- Cylinder of a measuring system was charged with required volume of oil.

- Reservoir temperature $\left(80{ }^{\circ} \mathrm{C}\right)$ was provided and maintained for $30 \mathrm{~min}$ for full wax dilution.

- Flow curve consists of three lines: forward line (shear rate was increased from 0 to $300 \mathrm{~s}^{-1}$ for $5 \mathrm{~min}$ ), straight line (maintenance shear rate of $300 \mathrm{~s}^{-1}$ for $5 \mathrm{~min}$ ) and backward line (decrease in shear rate from 300 to $0 \mathrm{~s}^{-1}$ for $5 \mathrm{~min}$ ).

- After that, temperature was decreased to the next step $\left(70{ }^{\circ} \mathrm{C}\right.$ ), oil was kept at this temperature for $30 \mathrm{~min}$, and experiment was carried out again.

As a result, 11 flow curves were obtained under atmospheric pressure over the temperature range from 80 to $26^{\circ} \mathrm{C}$.

Additionally, influence of chemicals on lattice formed by wax in oil was carried out by rheological method. Solvent was added to oil in concentration of $3 \%$ by weight. Experiment conditions were similar to mentioned above. Totally, 5 flow curves for oil with solvent were obtained over the temperature range from 80 to $40^{\circ} \mathrm{C}$.

Viscosity curve measuring technique with waxy oil was as follows:

- Oil was kept at a reservoir temperature $\left(80^{\circ} \mathrm{C}\right)$ in the measuring system until full wax dilution.

- Then, temperature was decreased with cooling rate of $1{ }^{\circ} \mathrm{C} / \mathrm{min}$, measuring was provided at shear rate of $2 \mathrm{~s}^{-1}$.

\section{Microscopy under high-pressure and light scattering method}

Influence of $\mathrm{N}_{2}$ and $\mathrm{CO}_{2}$ on WAT in waxy oil was investigated by microscopy under high-pressure and light scattering methods.

- PVT SDS cell, HPM cell and tubing were heated up to reservoir temperature of $80^{\circ} \mathrm{C}$ and vacuumized.

- $50 \mathrm{ml}$ of oil was injected into the PVT cell under reservoir pressure $(21 \mathrm{MPa})$ and temperature by pumps P1 and P4 (Fig. 1). Then, recirculation pump was switched on and oil was mixed in the system under reservoir pressure and temperature for $12 \mathrm{~h}$. Full wax dissolution in oil has been determined visually by a HPM (test accuracy is $10^{-6} \mathrm{~m}^{2}$ ) and the light scattering method (the energy registered on detector has stopped to change over time). Also volume of oil has stopped to change over time. The recirculation pump was switched off before the experiment.

- Then, temperature was decreased with a cooling rate of $0.2{ }^{\circ} \mathrm{C} / \mathrm{min}$ from 80 to $55^{\circ} \mathrm{C}$. The data of SDS system (light transmittance power) and HPM (oil micrographs) were recorded. Temperature at which sharp decrease in light transmittance power is observed was taken as WAT. WAT was also determined by appearance of solid organic particles in oil on micrographs.

- After that, the laboratory setup was cleaned with solvent and blown with compressed dry air.

Oil samples with $\mathrm{N}_{2}$ and $\mathrm{CO}_{2}$ in concentration of $10 \%$ by weight were investigated in the similar technique as mentioned above.

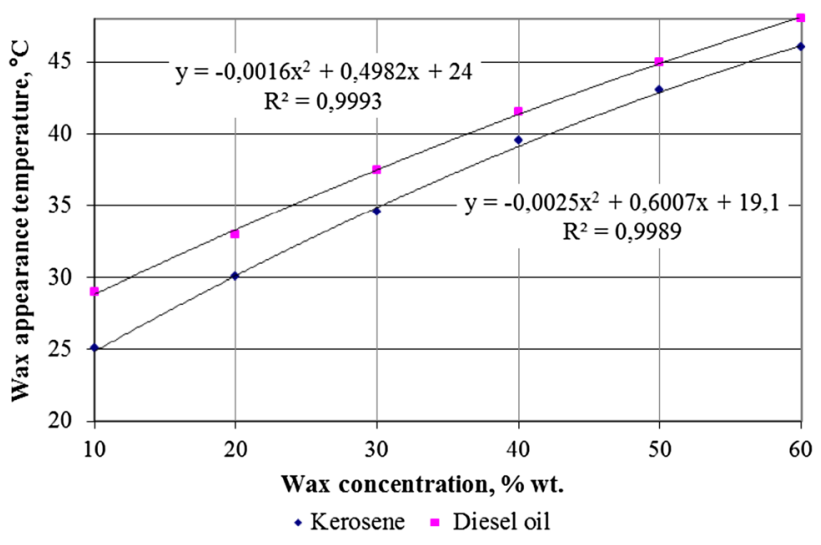

Fig. 2 Effect of wax concentration on WAT in the wax-bearing solutions by visual method 


\section{Analysis of experiment results}

\section{Investigation of wax-bearing solutions by visual method under atmospheric pressure}

WAT in wax-bearing solutions was measured at atmospheric pressure by a visual method. Solutions were prepared on the basis of kerosene and diesel fuel with different wax concentrations. Experimental results are presented in Fig. 2.

WAT in two solvents changes according to the quadratic relation and differs against each other on $2-4{ }^{\circ} \mathrm{C}$. Properties of wax in kerosene-based solutions are described more carefully in paper (Struchkov and Rogachev 2017a, b).

Diesel fuel is represented by more high molecular weight paraffin hydrocarbons compared to kerosene, and its properties are more similar to oil. Therefore, further experiments were provided with wax in diesel-based solutions. Effect of impurities on WAT was investigated wherefore kaolinite (size of $0.01 \mathrm{~mm}$ ) was added to solutions in concentrations of $0.1,0.5$ and $1 \mathrm{~g} / \mathrm{l}$. It is necessary to suspend large solid particles in solution during the study. Due to gravity settling, they are not suspended. Moreover, there was used equipment without stirrer in the experiment, so fine particles that could be prepared in an agate mortar were used. Experimental results are presented in Fig. 3.

Figure shows that the presence of kaolinite in solutions increases WAT measured by visual method by $1-2{ }^{\circ} \mathrm{C}$. Kaolinite is a fine flake of clay, some of which does settle in solution without stirring. However, the smallest ones are suspended in a heavy hydrocarbon solution. Such particles act as nucleation seeds of wax. Besides, it is known that heterogeneous nucleation (providing that there are any free surfaces of solid particles) is more favorable process in terms of thermodynamic properties compared to homogeneous

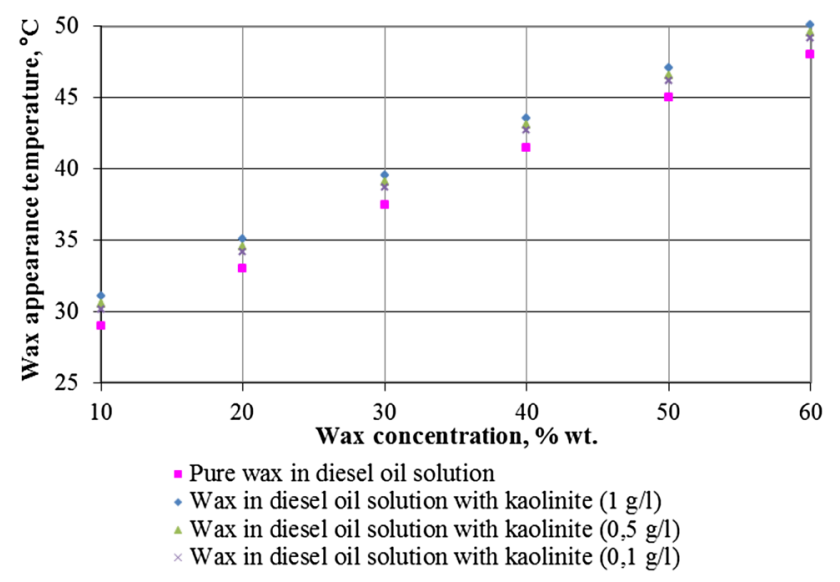

Fig. 3 Effect of wax and impurities concentration on WAT in the wax-bearing solutions by visual method nucleation of the new phase in bulk solution in the absence of solid particles. In other words, in the presence of impurities, WAT is higher than in the absence of impurities. This fact is known in both metallurgy and oil engineering. This problem is well studied in papers (Pantell and Puthoff 1969; Struchkov and Rogachev 2017a, b). Similar results are obtained by authors in paper (Hamitov et al. 2017) in which the waxy oil with impurities and pure original oil were investigated by light scattering and visual methods.

\section{Investigation of wax-bearing solutions by rheological method under atmospheric pressure}

Measurements of WAT in wax-bearing diesel-based solutions are carried out by rheological method via rotational viscometer. Experimental results are presented in Fig. 4.

The reflection point on a viscosity curve demonstrates appearance of wax solids in solution. Further temperature decrease leads to gelation and significant increase in effective viscosity caused by wax crystals. Gelation rate is defined by wax concentration in solution. Strength of lattice increases with the increase in wax concentration.

WAT measured by rheological method is higher than WAT measured by visual method, approximately on $1{ }^{\circ} \mathrm{C}$. It is associated with various sensitivity limits of the laboratory equipment for different research techniques.

Result investigations of diesel-based solutions with kaolinite are presented in Fig. 5.

The effective viscosity of wax-bearing solutions with kaolinite is higher than in pure solutions that indicate difference in internal friction mechanism. A significant number of wax crystals concentrate onto the free surface of crystal seeds (particles of kaolinite) and therefore enforced lattice with high viscosity forms, so WAT in solutions increases by means of $1-2{ }^{\circ} \mathrm{C}$.

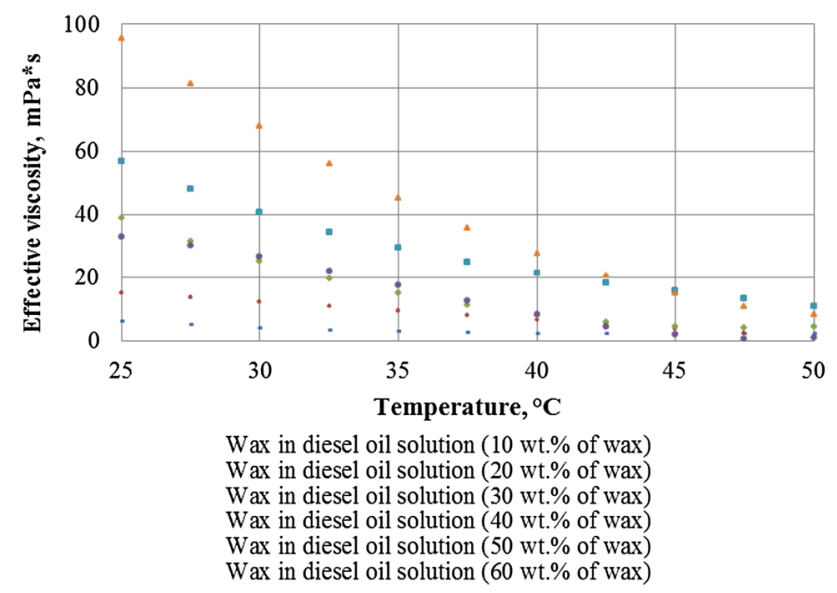

Fig. 4 Effect of temperature on viscosity of the wax-bearing solutions

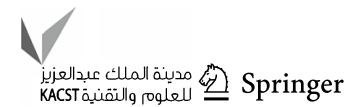




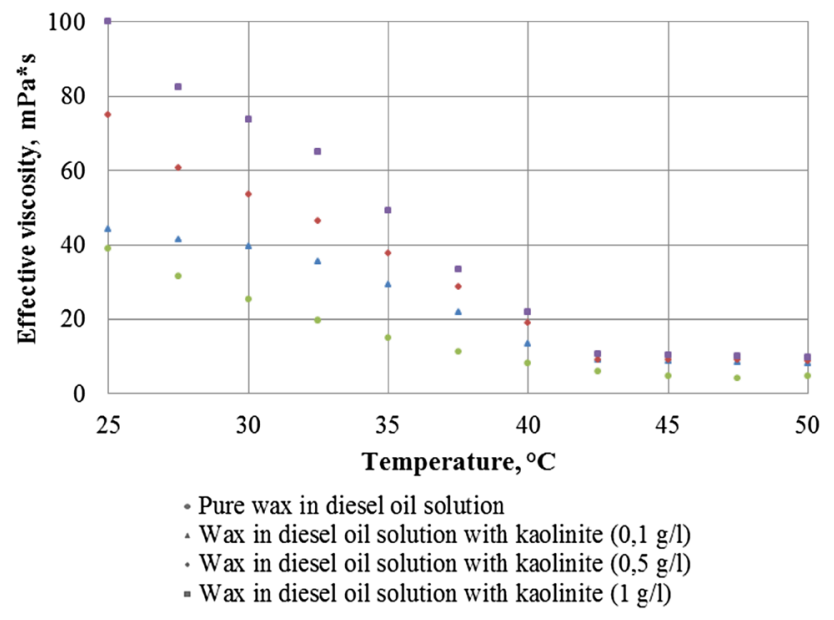

Fig. 5 Effect of temperature and kaolinite concentration on viscosity of wax-bearing solution (wax concentration of $30 \%$ wt.)

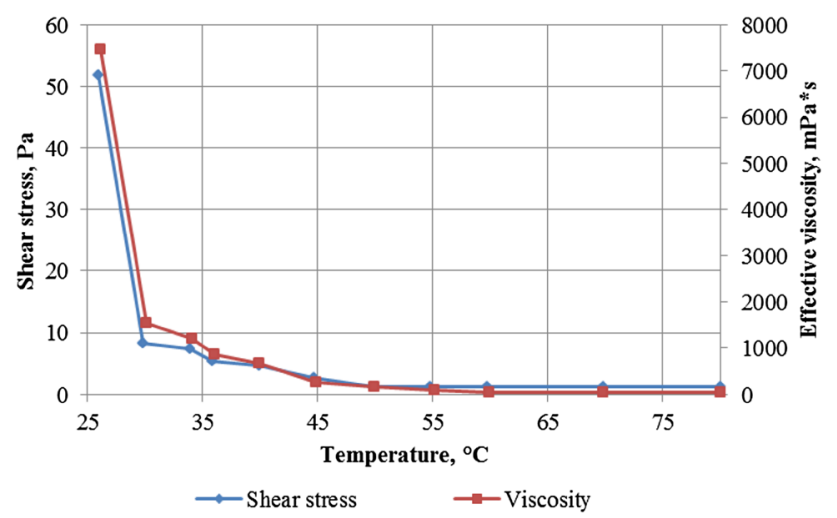

Fig. 6 Effect of temperature on shear stress and effective viscosity

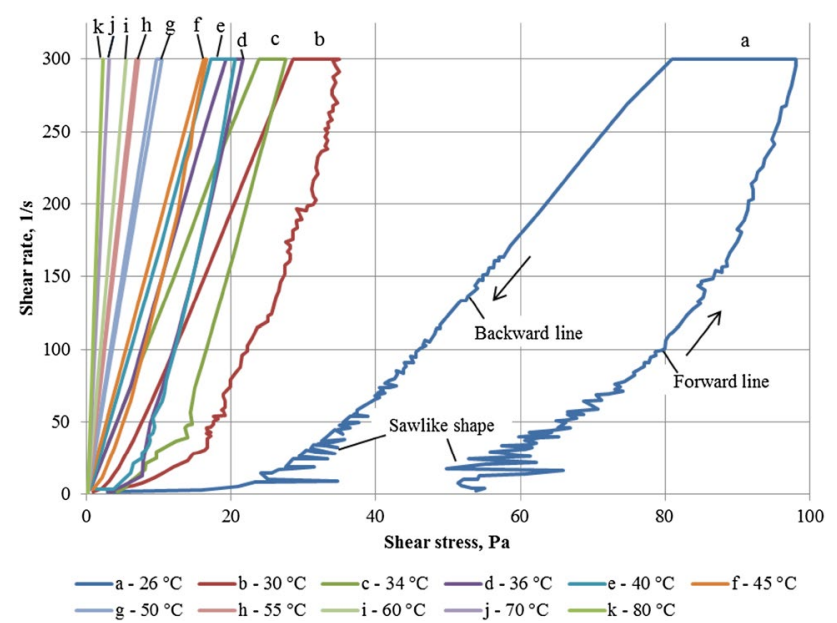

Fig. 7 Effect of shear rate on shear stress at different temperatures

\section{Investigation of waxy crude oil by rheological method under atmospheric pressure}

Result investigations of rheological properties of waxy oil are presented in Figs. 6 and 7.

The dependences of effective viscosity and shear stress of waxy oil on temperature are presented in Fig. 6. Measurements were carried out in the temperature range from $80^{\circ} \mathrm{C}$ (reservoir temperature) up to $26^{\circ} \mathrm{C}$ (the wellhead temperature). Steady viscosity growth with the decrease in temperature below $50{ }^{\circ} \mathrm{C}$ demonstrates formation of lattice in oil and its gelation due to the increase in a number of molecular bonds.

Flow curves at different temperatures are presented in Fig. 7. Figure shows that oil behaves as a Newtonian liquid under reservoir temperature $\left(80^{\circ} \mathrm{C}\right)$. Oil shows thixotropy at temperature of $50^{\circ} \mathrm{C}$ that reaches a peak at wellhead temperature $\left(26^{\circ} \mathrm{C}\right)$. Thixotropy is the ability of non-Newtonian liquid to restore lattice with time under the absence of shear. In other words, the smaller flow units combine into larger aggregates with the decrease in shear rate. On the other hand, the application of shear rate breaks down the lattice over time (Dimitriou 2013; Kirsanov and Remizov 1999). Oil thixotropic behavior at temperatures lower than reservoir temperature is caused by the presence of high amount of wax, asphaltenes and resins in oil. It is difficult to estimate WAT accurately from Figs. 6 and 7 due to the sensitivity of a measuring system. The lattice appears at a temperature of $50^{\circ} \mathrm{C}$. It may take a while to form the lattice by organic scales. Therefore, WAT can be essentially higher than $50^{\circ} \mathrm{C}$ for this oil.

Oil shows quasi-solid properties under wellhead temperature that increases operating costs (Lake et al. 2007). The flow curve at $26^{\circ} \mathrm{C}$ at low shear rates has a sawlike shape, which is explained by the following mechanism. The presence of certain amount of asphaltenes in waxy oil tends to the formation of coagulation-crystallization lattice by solid organic particles. In such oils, there are no stable strong bonds between solids under shear stress. The two following processes are carried out simultaneously in oil: destruction and restoration of bonds between solid particles. Bond strength depends on the equilibrium of forces acting in oil. If the shear stress exceeds the interaction forces between the organic particles, the lattice in oil is destroyed (sharp decrease in shear stress with the increase in shear rate in the forward line of the flow curve). If the shear stress is less than the interaction forces between the organic particles, the lattice in the oil is restored (sharp increase in shear stress with the increase in shear rate in the forward line of the flow curve as well as the sharp increase in shear stress with the decrease in shear rate in the backward line of the flow curve) (Vinogradov and Malkin 1966).

The area of hysteresis loop causes interaction energy between wax crystals. The increase in the area of hysteresis loop with temperature decrease is associated with consolidation of lattice. We have assumed that the area of the hysteresis 
loop in flow curve can be used to calculate the energy to destroy the lattice formed by wax in oil. This energy can be calculated by the following equation:

$E=M * w * t$,

where $M$-torque, $\mathrm{N}^{*} \mathrm{~m}, w$-rotary speed, $\mathrm{s}^{-1}, t$-time, required to destroy the lattice formed by wax, $s$.

It is required to treat oil with such amount of energy to destroy lattice and increase in oil mobility. This can be used in the designing of heat, chemical or other oil treatments.

The well operating conditions allow injecting chemicals into the well. Using of chemicals during waxy oil production increases in wells operating time and decreases in operating costs (Leaute 2002).

Flow curves at temperature ranges from 40 to $80{ }^{\circ} \mathrm{C}$ for initial oil and oil with solvent in concentration of $3 \%$ by weight are presented in Fig. 8. Figures 7 and 8 show that solvent considerably reduces the oil thixotropy.

Therefore, chemicals are recommended to use along with thermal methods that will facilitate mitigation of thixotropic oil characteristics and decrease in oil viscosity.

\section{Investigation of waxy crude oil by microscopy under high-pressure and light scattering method}

Gas injection can be used successfully apart from thermal and chemical methods in oil fields. So Huff and puff treatments with $\mathrm{CO}_{2}$ in heavy oil fields of the Samara region are resumed (Volkov et al. 2017). The heavy oil production steadily grows every year. A large number of heavy oil fields are located in the Samara region. The mobile well treatment unit was developed by Volkov, and pilot project was carried out. Oils of these fields were investigated in the paper (Lobanov et al. 2018), and application perspectiveness of Huff and puff treatments with $\mathrm{CO}_{2}$ was estimated. It is

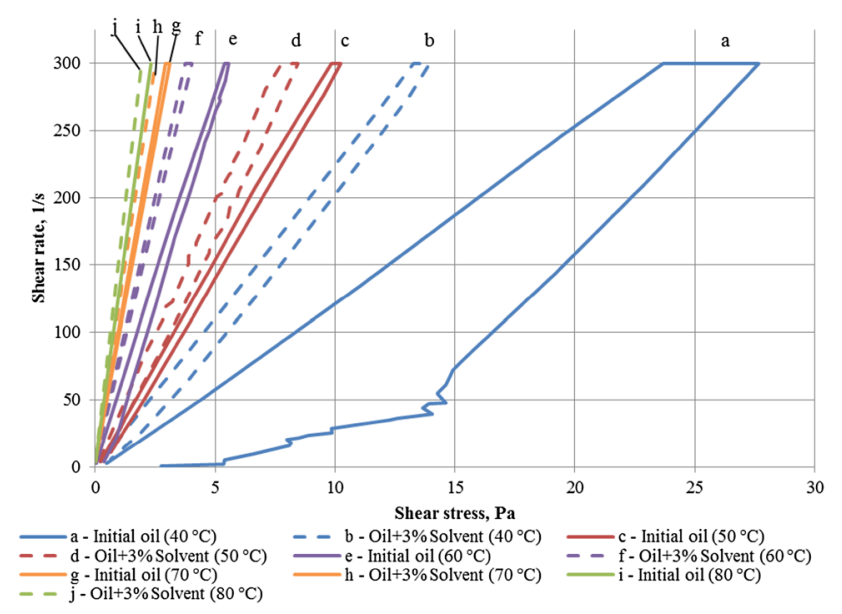

Fig. 8 Effect of shear rate on shear stress at different temperatures and solvent additions shown that the efficiency of $\mathrm{CO}_{2}$ injection is observed in the narrow concentration range in oil. Besides, the possibility of asphaltenes precipitation and deposition increases that the sustainability of this technology in the fields of the Samara region decreases. It is known that asphaltene scales are hard to remove. Treatment with aromatic solvents may act as the most likely removal method.

In this paper, authors investigated separate interaction between carbon dioxide, nitrogen and oil and influence of gases on WAT. Investigations were provided by microscopy under high-pressure and light scattering methods. The light scatter theory was developed by the British physical scientist and mechanician John William Strett. Light beam, passing through a system, can be absorbed, reflected or dissipated according to a set of conditions. Dissipation consists in conversion of light beam by the matter in their interaction which is provided with change of the light guidance (Valasek 1949). Measured properties depend on ratio between the wavelength of light beam and particle sizes of solid phase.

Results are presented in Figs. 9, 10 and 11.

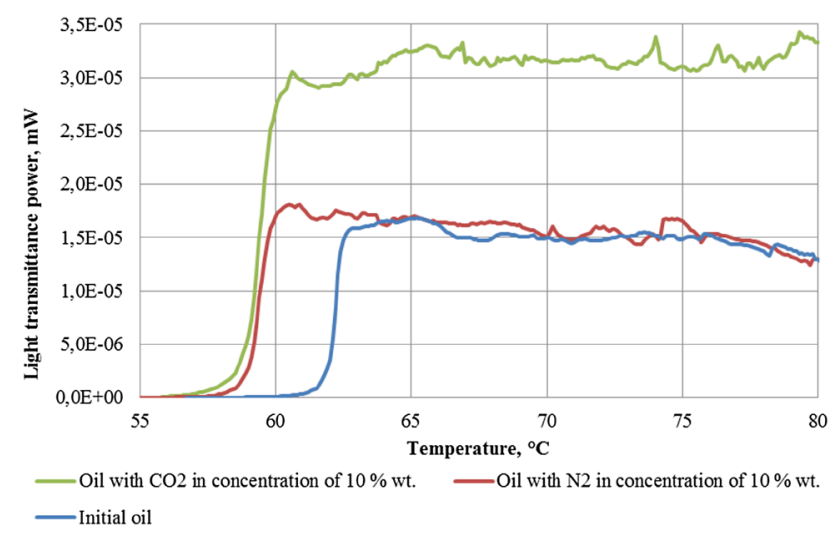

Fig. 9 Effect of temperature on light transmittance power at reservoir pressure (21 MPa)

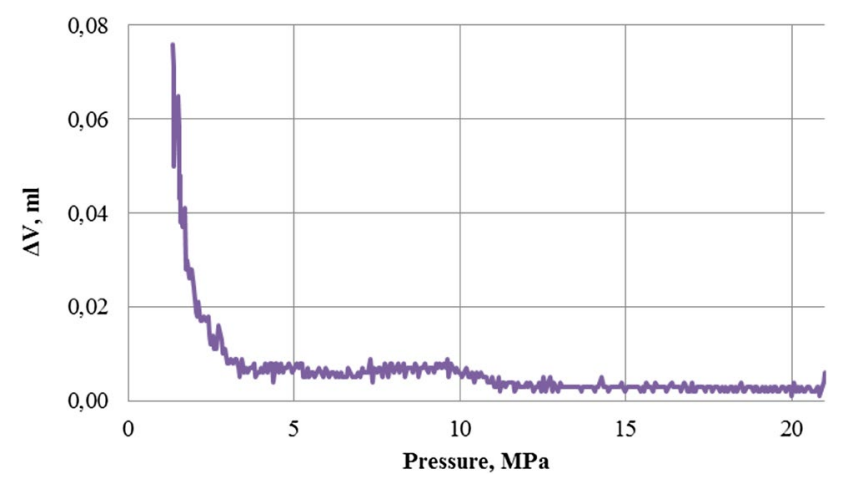

Fig. 10 Effect of pressure on volumetric gain $(\Delta V)$ of the system at temperature of $52^{\circ} \mathrm{C}$

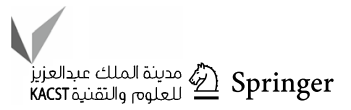


Fig. 11 Micrographs of oil samples at temperature decrease and reservoir pressure
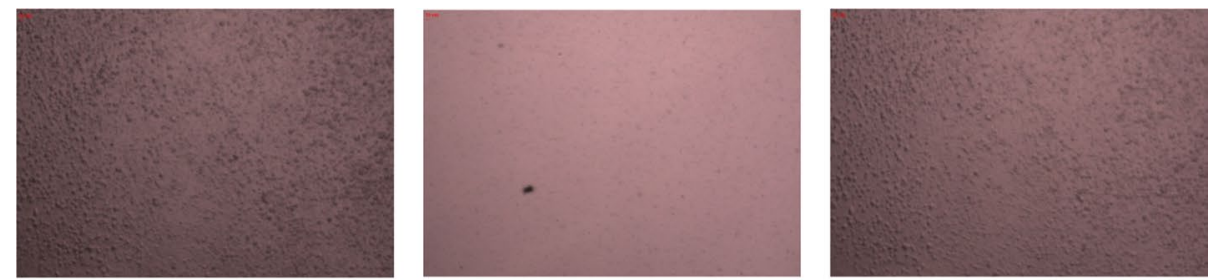

$80^{\circ} \mathrm{C}$
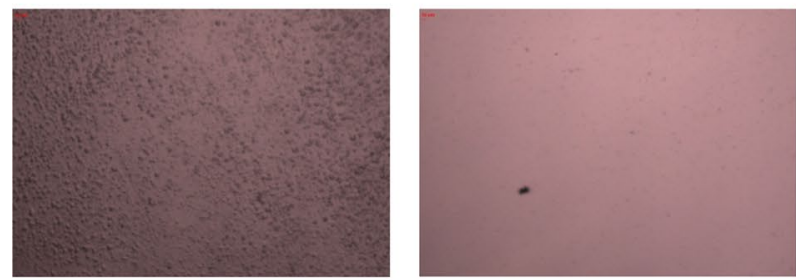

$70^{\circ} \mathrm{C}$
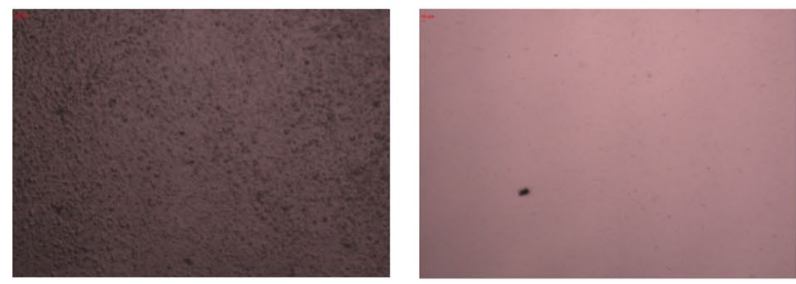

$63^{\circ} \mathrm{C}$
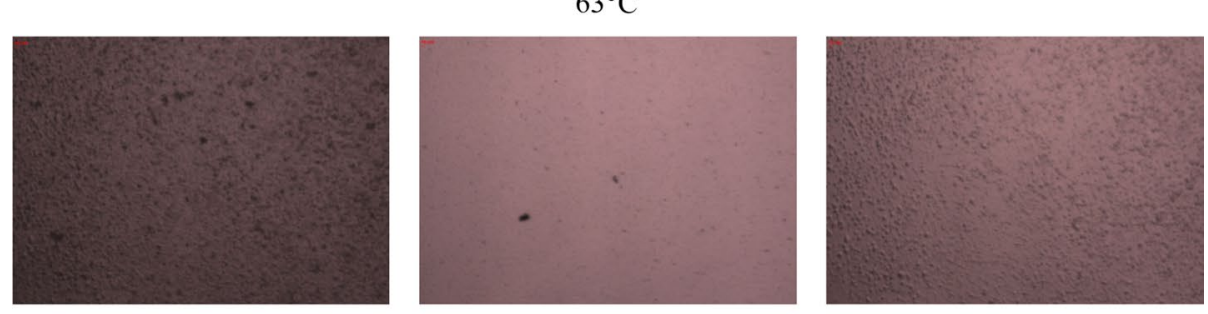

$62^{\circ} \mathrm{C}$
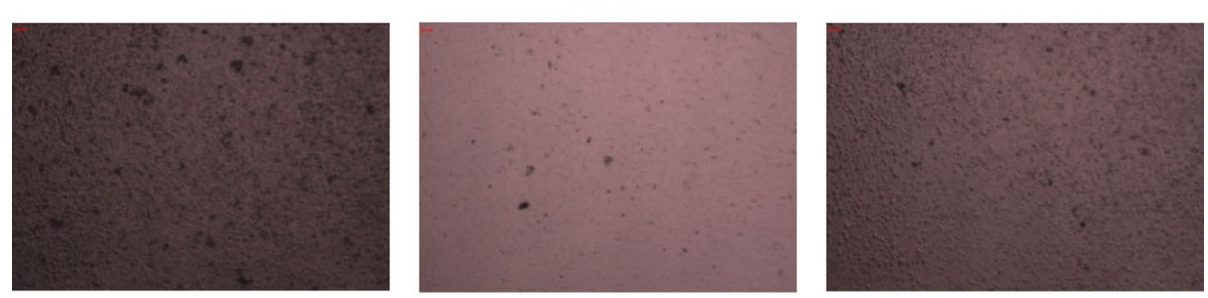

$61^{\circ} \mathrm{C}$
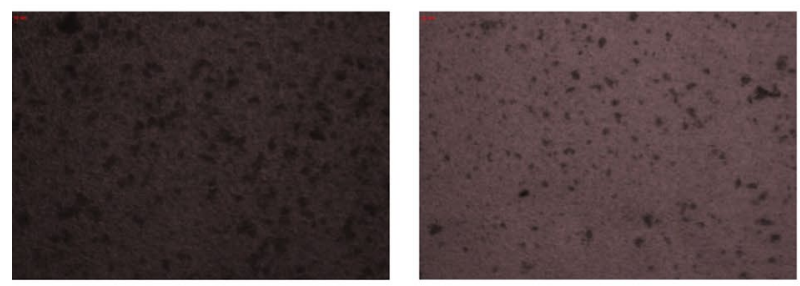

$55^{\circ} \mathrm{C}$

Oil with $\mathrm{CO}_{2}$ in concentration

Initial oil
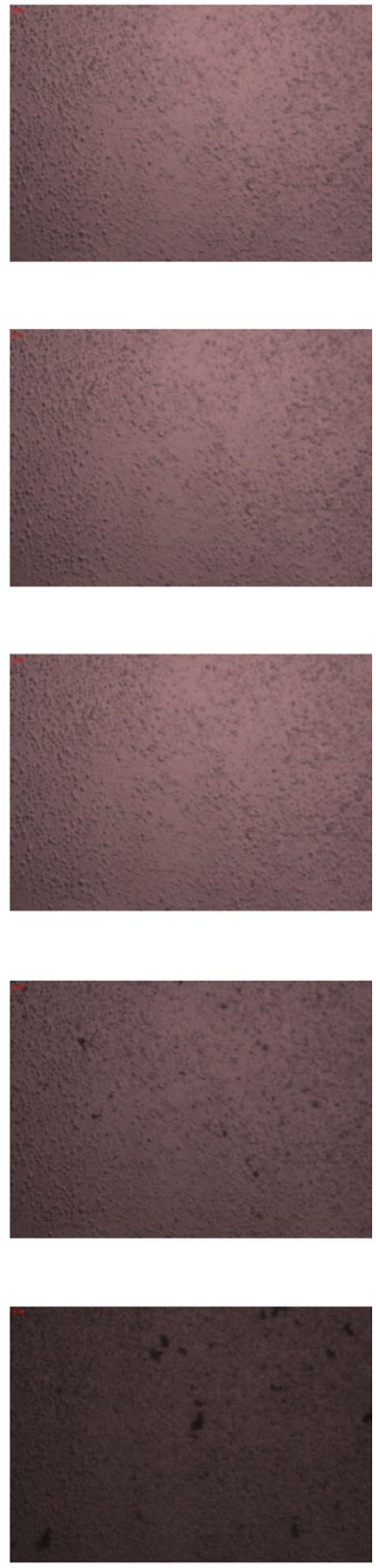

Oil with $\mathrm{N}_{2}$ in concentration of $10 \%$ wt. $10 \% \mathrm{wt}$. 
Figure 10 shows effect of pressure on volumetric gain $(\Delta V)$ of the system at temperature of $52{ }^{\circ} \mathrm{C}$ (the data of main pump). There is an inflection point on a curve at pressure of $3.9 \mathrm{MPa}$ in the figure which demonstrates $\mathrm{CO}_{2}$ liberation from oil. The study was carried out under single-contact interaction of oil and $\mathrm{CO}_{2}$. The increase in bubble point pressure to $3.9 \mathrm{MPa}$ (bubble point pressure is also confirmed by microscopy under high pressure) indicates dissolution of some volume of $\mathrm{CO}_{2}$ in oil.

Micrographs obtained by microscopy under high pressure at various temperatures are presented in Fig. 11.

Figure shows that $\mathrm{CO}_{2}$ in concentration of $10 \%$ by weight in oil leads to decrease in WAT on $1{ }^{\circ} \mathrm{C}$ (the first wax crystals in oil appear at $62{ }^{\circ} \mathrm{C}$ compared with $63{ }^{\circ} \mathrm{C}$ for the original oil). Similar results were obtained in the study (Pan et al. 1997), where the addition of $\mathrm{CO}_{2}$ at a concentration of $30 \%$ by weight to oil resulted in a reduction in cloud point by $2{ }^{\circ} \mathrm{C}$, while $\mathrm{N}_{2}$ in concentration of $10 \%$ by weight in oil leads to decrease in WAT on $2{ }^{\circ} \mathrm{C}$ compared to the original oil.

It is also known that the effect of $\mathrm{CO}_{2}$ on asphaltenes has an effect on reservoir oils. For dead oils in which the asphaltenes presented in a stable state, the effect of $\mathrm{CO}_{2}$ may be significantly lower. The authors would like to notice that the amount of asphaltenes and resins in studied oil is $5 \%$ by weight, and wax is $32 \%$ by weight, so the effect of $\mathrm{CO}_{2}$ was primarily considered on wax rather than asphaltenes. However, the authors do not exclude asphaltene precipitation in experiments with $\mathrm{CO}_{2}$. The use of $\mathrm{CO}_{2}$ in this study is not considered as a stand-alone option to wax control and cannot be considered as a commercially relevant technique. Huff and puff pilot projects of producers with $\mathrm{CO}_{2}$, as a well stimulation technique, are carried out at heavy oil fields in the Samara region. This paper considers the effect of $\mathrm{CO}_{2}$ on WAT as one of the possible consequences of the implementation of huff and puff technology. The authors studied in more detail the influence of $\mathrm{CO}_{2}$ on asphaltenes in one of the Samara oil fields in the following paper (Lobanov et al. 2018). In this paper, the authors show the negative effect of $\mathrm{CO}_{2}$ on asphaltenes.

Gas injection is not used as prevention of organic scale formation due to a number of factors (economic, technological, etc.). However, use of $\mathrm{CO}_{2}$ during Huff and Puff treatment of heavy oil reservoirs may cause reduction in wax formation in the oil production system. However, it is necessary to retain that comprehensive laboratory investigations are required before implementation of the pilot projects. Interaction between $\mathrm{CO}_{2}$ and certain oil types in most cases leads to asphaltene precipitation.

\section{Conclusions}

Investigations of the wax-bearing solutions by visual and rheological methods allowed to conclude the following:

- WAT increases with the increase in wax concentration in solution.

- WAT increases with the addition of impurities (kaolinite) and strengthens the lattice formed by wax crystals.

Rheological studies of waxy crude oil showed the following:

- The studied waxy oil at the reservoir temperature behaves as Newtonian liquid, but it shows thixotropic characteristics with the decrease in temperature. At the wellhead temperature, oil shows quasi-solid properties that complicate oil production.

- The area of a hysteresis loop characterizes the energy necessary to destroy the lattice in oil formed by wax and the increase in oil mobility. Investigations showed that the effective control methods with viscosity anomaly of oil are thermal and chemical.

Studies with gas injection to waxy oil showed the following:

- $\mathrm{N}_{2}$ and $\mathrm{CO}_{2}$ reduce WAT in oil, and the best results were shown by $\mathrm{N}_{2}$. However, there is a risk of asphaltene precipitation in oil and organic scale formation in reservoir and downhole equipment.

Acknowledgements We acknowledge Dr. M.K. Rogachev and A.V. Petukhov for their assistance during the experiments. Finally, we would like to thank Saint-Petersburg Mining University (Saint Petersburg, Russia) for providing laboratory equipment support and samples for this research.

Open Access This article is distributed under the terms of the Creative Commons Attribution 4.0 International License (http://creativeco mmons.org/licenses/by/4.0/), which permits unrestricted use, distribution, and reproduction in any medium, provided you give appropriate credit to the original author(s) and the source, provide a link to the Creative Commons license, and indicate if changes were made.

\section{References}

Akbarzadeh K, Hammami A, Kharrat A, Zhang D, Allenson S, Creek J, Mullins OC (2007) Asphaltenes-problematic but rich in potential. Oilfield Rev 19(2):22-43

Al-Ahmad M, Al-Fariss T, Obaid-ur-Rehman S (1990) Solubility studies on a wax in base oils. Fuel 69(3):293-296

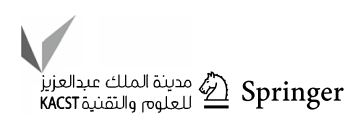


Amine B, Maurel P, Agassant JF, Darbouret M, Avril G, Peuriere E (2008) Wax deposition in pipelines: flow-loop experiments and investigations on a novel approach. In: SPE annual technical conference and exhibition. Society of Petroleum Engineers

Bern PA, Withers VR, Cairns RJ (1980) Wax deposition in crude oil pipelines. In: European offshore technology conference and exhibition. Society of Petroleum Engineers

Bidmus HO, Mehrotra AK (2004) Heat-transfer analogy for max deposition from waxy mixtures. Ind Chem Res 43:3-791

Bortolin L, Uzcategui E (1992) New experience with electrical submersible pumps in heavy oil crude. In: SPE Latin America petroleum engineering conference. Society of Petroleum Engineers

Brown K (1985) Artificial lift. Pen Wells Books, Tulsa

Brown TS, Niesen VG, Erickson DD (1993) Measurement and prediction of the kinetics of paraffin deposition. In: SPE annual technical conference and exhibition. Society of Petroleum Engineers

Chi Y, Daraboina N, Sarica C (2017) Effect of the flow field on the wax deposition and performance of wax inhibitors: cold finger and flow loop testing. Energy Fuels 31(5):4915-4924

Dimitriou C (2013) "The rheological complexity of waxy crude oils: yielding, thixotropy and shear heterogeneities"

Ferris SW, Cowles HC Jr, Henderson LM (1931) Composition and crystal form of the petroleum waxes. Ind Eng Chem 23(6):681-688

Fong N, Mehrotra AK (2007) Deposition under turbulent flow of wax-solvent mixtures in a bench-scale flow-loop apparatus with heat transfer. Energy Fuels 21(3):1263-1276

García MDC (2000) Crude oil wax crystallization. The effect of heavy n-waxs and flocculated asphaltenes. Energy Fuels 14(5):1043-1048

Gonzalez D, Jamaluddin AKM, Solbakken T, Hirasaki G, Chapman W (2007) Impact of flow assurance in the development of a deepwater project. In: Prepared for presentation at the SPE annual technical conference and exhibition, Anaheim, California

Goual L (2012) Petroleum asphaltenes. INTECH Open Access Publisher, London

Gudmundsson JS, Bott TR (1977) Solubility of wax in kerosene. Fuel 56(1):15-16

Gunarathne GPP (1995) «Novel techniques for monitoring and enhancing dissolution of mineral deposits in petroleum pipelines». In: Offshore Europe conference, Aberdeen

Gürü M, Karakaya U, Altıparmak D, Alıcilar A (2002) Improvement of diesel fuel properties by using additives. Energy Convers Manag 43(8):1021-1025

Halstensen M, Arvoh BK, Amundsen L, Hoffmann R (2013) Online estimation of wax deposition thickness in single-phase sub-sea pipelines based on acoustic chemometrics: a feasibility study. Fuel 105:718

Halvorsen VH, Lervik JK, Klevjer G (2000) Hydrate and wax prevention of risers by electrical heating. In: The tenth international offshore and polar engineering conference. International Society of Offshore and Polar Engineers

Hamitov IG, Petrov NA, Struchkov IA, Roshchin PV, Manasyan AEH, Pavlov PV (2017) Complications during production of waxy oil with impurities. Oilfield Eng 1:36-40

Hirasaki GJ, Chapman WG (2007) Impact of flow assurance in the development of a deepwater prospect

Idris M, Okoro LN (2013) The effects of asphaltenes on petroleum processing. Eur Chem Bull 2(6):393-396

Kapusta SD, van den Berg F, Daane R, Place MC (2003) The impact of oil field chemicals on refinery corrosion problems. In: CORROSION 2003. NACE International

Kirsanov EA, Remizov SV (1999) Application of the Casson model to thixotropic waxy crude oil. Rheol Acta 38(2):172-176
Kok MV et al (1996) Comparison of wax appearance temperatures of crude oils by differential scanning calorimetry, thermomicroscopy and viscometry. Fuel 75(7):787-790

Kriz P, Andersen SI (2005) Effect of asphaltenes on crude oil wax crystallization. Energy Fuels 19(3):948-953

Lake LW, Fanchi JR, Arnold K, Clegg JD, Holstein ED, Warner HR (2007) Petroleum engineering handbook: reservoir engineering and petrophysics, vol 5. Society of Petroleum Engineers.

Leaute RP (2002) Liquid addition to steam for enhancing recovery (LASER) of bitumen with CSS: evolution of technology from research concept to a field pilot at Cold Lake. In: SPE international thermal operations and heavy oil symposium and international horizontal well technology conference. Society of Petroleum Engineers

Lei Y, Han S, Zhang J, Bao Y, Yao Z, Xu YN (2014) Study on the effect of dispersed and aggregated asphaltene on wax crystallization, gelation, and flow behavior of crude oil. Energy Fuels 28(4):2314-2321

Li H, Gong J (2010) The effect of pressure on wax disappearance temperature and wax appearance temperature of water cut crude oil. In: The twentieth international offshore and polar engineering conference. International Society of Offshore and Polar Engineers

Lobanov A, Shhekoldin K, Struchkov I, Zvonkov M, Hlan M, Pustova E, Kovalenko V, Zolotukhin A (2018) Swelling/extraction test of Russian reservoir heavy oil by liquid carbon dioxide. Pet Explor Dev 45(5):918-926

Lordo S, Garcia JM, Swofford SG (2008) Desalter acidification additives and their potential impacts on crude units. In: CORROSION 2008. NACE International

Mansoori GA (1997) Modeling of asphaltene and other heavy organic depositions. J Pet Sci Eng 17(1):101-111

McMullin JN, Eastman CD, Pulikkaseril C, Adler D (1999) Measurement of the wax appearance temperature in crude oil by laser scattering. In: 1999 IEEE canadian conference on electrical and computer engineering, vol 3. IEEE, pp 1755-1758

Pan H, Firoozabadi A, Fotland P (1997) Pressure and composition effect on wax precipitation: experimental data and model results. SPE Prod Facil 12(04):250-258

Pantell RH, Puthoff HE (1969) Fundamentals of quantum electronics. Wiley, Hoboken

Parthasarathi P, Mehrotra AK (2005) Solids deposition from multicomponent wax-solvent mixtures in a benchscale flow-loop apparatus with heat transfer. Energy Fuels 19(4):1387-1398

Paso K, Kallevik H, Sjoblom J (2009) Measurement of wax appearance temperature using near-infrared (NIR) scattering. Energy Fuels 23(10):4988-4994

Shepherd JE, Nuyt CD, Lee JJ, Woodrow JE (2000) Flash point and chemical composition of aviation kerosene (Jet A). Graduate Aeronautical Laboratories California Institute of Technology Pasadena. Explosion Dynamics Laboratory Report FM99-4

Singh P, Venkatesan R, Fogler HS, Nagarajan N (2000) Formation and aging of incipient thin film wax-oil gels. AIChE $\mathrm{J}$ 46(5):1059-1074

Srivastava SP, Saxena AK, Tandon RS, Shekher V (1997) Measurement and prediction of solubility of petroleum waxes in organic solvents. Fuel 76(7):625-630

Struchkov IA, Rogatchev MK (2014) An impact analysis of a nonionic surfactant on the organics state in an oil sample when modelling downhole conditions. Jelektronnyj nauchnyj zhurnal Neftegazovoe delo 5:104-118

Struchkov IA, Roschin PV (2016) Effect of light hydrocarbons on wax precipitation. Int J Appl Eng Res 11(16):9058-9062

Struchkov IA, Rogachev MK (2017a) Risk of wax precipitation in oil well. Nat Resour Res 26(1):67-73 
Struchkov IA, Rogachev MK (2017b) Wax precipitation in multicomponent hydrocarbon system. J Pet Explor Prod Technol 7(2):543-553

Struchkov IA, Rogachev MK (2018) The challenges of waxy oil production in a Russian oil field and laboratory investigations. J Pet Sci Eng 163:91-99

Struchkov IA, Hamitov IG, Roshchin PV, Manasyan AEH (2016) Physical and chemical scales-control methods during operation of the field of waxy oil. Oilfield Eng 4:48-52

Struchkov IA, Rogachev MK, Kalinin ES, Pavlov PV, Roschin PV (2018) Laboratory investigation of organic-scale prevention in a Russian oil field. SPE Prod Oper 33(01):113-120

Struchkov IA, Rogachev MK, Kalinin ES, Roschin PV (2019) Laboratory investigation of asphaltene-induced formation damage. $\mathrm{J}$ Pet Explor Prod Technol 9(2):1443-1455

Taheri-Shakib J, Shekarifard A, Naderi H, Hosseini SA (2017) "Effect of microwave irradiation on wax and asphaltene content of heavy crude oil." In: 79th EAGE conference and exhibition 2017

Taheri-Shakib J, Shekarifard A, Naderi H (2017b) The experimental investigation of effect of microwave and ultrasonic waves on the key characteristics of heavy crude oil. J Anal Appl Pyrol 128:92-101

Taheri-Shakib J et al (2018a) A comprehensive study of the impact of wax compositions on the wax appearance temperature (WAT) of some Iranian crude oils: an experimental investigation. J Pet Sci Eng 165:67-80
Taheri-Shakib J et al (2018b) Characterization of the wax precipitation in Iranian crude oil based on wax appearance temperature (WAT): part 1. The influence of electromagnetic waves. J Pet Sci Eng 161:530-540

Valasek J (1949) Introduction to theoretical and experimental optics. Wiley, Hoboken

Vinogradov GV, Malkin AY (1966) Comparative description of the peculiarities of deformation of polymer and plastic disperse systems. Rheol Acta 5(3):188-193

Volkov VA, Prohorov PJe, Turapin AN, Afanasiev SV (2017) Cycle injection of carbon dioxide into production wells for stimulation. J Theory Pract Appl Enhanced Oil Recovery Methods (1):31-33 (In Russia)

Wu CH, Wang KS, Shuler PJ, Tang Y, Creek JL, Carlson RM, Cheung S (2002) Measurement of wax deposition in wax solutions. AIChE J 48(9):2107-2110

Zadeh KA, Tatavalli-Mittadar N, Abd-Rahman A, Jain S, Ashtekar S, McGregor S, Degaleesan S (2018) Enhanced solvent-based remediation of waxy deposits. In: Abu Dhabi international petroleum exhibition \& conference. Society of Petroleum Engineers

Publisher's Note Springer Nature remains neutral with regard to jurisdictional claims in published maps and institutional affiliations.

\section{Affiliations}

\section{A. Struchkov ${ }^{1}$ (I) P. V. Roschin ${ }^{2} \cdot$ V. T. Litvin ${ }^{2} \cdot$ V. A. Ol'hovskaya ${ }^{1}$ - E. S. Kalinin ${ }^{3}$}

1 Development and Exploitation of Oil and Gas Fields"

3 LLC SamaraNIPIneft, Samara, Russia

Department, Samara State Technical University,

Molodogvardeyskaya Street, Building 244, Samara,

Russia 443100

2 LLC Akribia Lab, Samara, Russia 